\title{
DOES THE NATURE OF INDEX AND LIQUIDITY INFLUENCE THE MISPRICING IN FUTURE CONTRACTS IN INDIA?
}

\author{
DEEKSHA GARG1, KARAM PAL NARWALI
}

1. Guru Jambheshwar University of Science \& Technology, Hisar, Haryana

* Corresponding Author: Deeksha Garg, Research Scholar, Guru Jambheshwar University of Science and Technology, Haryana, India.

I +00 (844) $7532920 \bowtie$ deekshagarg99@gmail.com

\begin{abstract}
In this study, we investigate the variations in the mispricing of futures in Nifty (benchmark index), Bank Nifty and Nifty IT. Using a regression model on 1230 observations for the period of 1 January 2014 to 31 December 2018, we find no significant mispricing exists in the last week to the expiry of the contract in all three indices. This finding supports the existing literature that as the contract moves towards the maturity date, its value converges the market value. However, the main highlight of the paper is to reveal the difference in the life of mispricing in different indices. This difference in mispricing can be allocated to the liquidity in that indice. We report that being the most liquid, Bank Nifty shows mispricing only in 1 week (first week) of the contract. No significant mispricing exists thereafter. Nifty shows significant mispricing for the first two weeks and Nifty IT shows mispricing for all, except the last week. This is the pioneering work which considers the sectoral differences while evaluating futures mispricing. The findings of this study will provide useful insight to the regulators and investors.
\end{abstract}

Keywords: Cost of carrying model, mispricing, sectoral indices, arbitrage.

\section{Introduction}

Pricing of the futures contract is extensively researched in the finance literature. Since the introduction of index futures in various international markets at different point of time, several studies have been undertaken on arbitrage and price dynamics in the index futures market. For pricing of the futures, the cost of carrying model serves as the benchmark model. Applicability of this model has been explored in different markets by various authors such as Figlewsky (1984), Yadav and Pope (1990), Bailey (1989), Fassas (2010) and Nandan et al. (2014) in US, UK, Japanese, Greek stock market and Indian futures market respectively. In the Spanish market, Verdasco (2016) confirmed the compliance of the cost of carrying model, and it has been deemed fit for pricing of index futures.

Theoretically, the price of the futures contract should be the price of the underlying asset plus the cost of carrying that future contract. However, in real-world, this rarely happens, either the future price is less than the theoretical price or more than the theoretical price. The deviation from the theoretical price is known as mispricing in the futures contract. Both instances, i.e. underpricing or overpricing, also known as mispricing, provides a riskless arbitrage opportunity to the traders. Previous studies by Cornell and French (1983), Modest and Sundaresan (1983), Buhler and Kempf (1995), Brenner et al. (1989), Pope and Yadav (1994), Vipul (2005), Andreou and Pierides (2008), Figlewski (2016), Lai (2017), Lepoene (2019) and Qin et al. (2019) have reported substantial underpricing in the index futures in different markets around the world. On the other hand, Mackinlay and Ramaswamy (1988), Bhatt and Cakici (1990), Fung and Draper (1999), Draper and Fung (2003), Chu and Hsieh 
(2002) and Richie et al. (2008) observed positive mispricing in their respective markets. Vipul (2005) found that futures in India are persistently underpriced. Even in the IPO segment, Gupta et al. (2019) found that the IPOs are underpriced to the extent of 12 percent in the Indian market. Lepoene (2019) examined the impact of short selling restrictions on the futures mispricing in the Chinese markets and observed it imposes additional costs to the arbitrage strategies leading to persistent underpricing. In the Hong Kong futures market, Fung and Draper (1999) found that government intervention impeded arbitrage efficiency as well as liquidity in the market. The problem of underpricing in the futures market can be resolved by lifting short sale constraints (Fung \& Draper, 1999), Marcinkiewicz (2016).

However, all these past studies, consider the benchmark index, for instance, NIFTY in case of India. The index comprises of the top securities based on market capitalization like NIFTY comprises of top 50 companies of India based on market capitalization. It implies studying mispricing of an Index will provide us with a picture of the top companies in a country. It also raises an important question, i.e. what about other companies which are not in the top list or do companies which are similar in characteristics like banking companies or IT companies shows a similar pattern for mispricing? Since the benchmark index analysis tends to hide the true picture as it may miss out the behavioural aspect of index mispricing. Therefore, the in-depth analysis of sectoral difference might highlight another dimension to the mispricing in index futures. There is very scant literature available which studies mispricing in different sectors, motivating us to study sectoral mispricing in India.

Butterworth and Holmes (2000) critically examined the pricing efficiency of the FTSE 100 and FTSE mid 250 index futures contract traded in the UK. Due to less liquidity in the Mid 250 contracts, as compared to FTSE 100, more substantial mispricing was observed in the Mid 250 index contracts. It implies that the liquidity of the contract is also playing a significant role in explaining the mispricing. However, to the best knowledge of the author, there is no study which relates the liquidity to the life of the mispricing of the contract. This study is an attempt to fill this gap in the literature.

This paper highlights that the liquidity of a stock or index affects its life of mispricing. Further, liquidity is having an inverse relationship with the life of the mispricing. It implies that higher the liquidity, less will be the life of the mispricing or vice-versa. Here, the life of mispricing means the period for which the mispricing continues. In this paper, the period is measured in terms of a week. As the liquidity of bank nifty is much higher than Nifty IT, this study expects that life of mispricing will be more for Nifty IT than Bank Nifty. This is more logical as well because higher liquidity implies more trading, which means more information to the market, which results in converging price towards the actual price of the security.

The paper finds that mispricing disappears in the last week to expiry for all three indices, highlights the convergence of the price when the security is near to its maturity. Also, the traders unwind their positions in the last week, resulting in no significant mispricing. The Nifty index shows significant mispricing for the first two weeks, then little mispricing is observed in the remaining week to expiry. Bank Nifty shows significant mispricing for the first week, then no significant mispricing noted in the remaining week to expiry. Nifty IT reveals significant mispricing for the entire period except for last week to expiry. These results are quite insightful as they highlight how the liquidity of an index affects the life of the mispricing. This paper is organized as follows. Section 2 presents data and the methodology used in the paper. Section 3 provides the results of the study. Finally, Section 4 concludes the study.

\section{Data and Methodology}

Daily closing prices have been obtained for all three sectors from the official website of the National Stock Exchange (NSE) of India (nseindia.com). Since there is significantly less liquidity observed for the far month contracts, therefore, we have used daily closing prices for the near month contracts. It is consistent with the literature as well (Nandan et al., (2015), Vipul (2005)). Mumbai Inter-Bank Offer Rate (MIBOR) rate has been taken as a proxy for the risk-free rate of interest. The data for 1-month 
term MIBOR rates have been extracted from the Financial Benchmarks India Pvt. Ltd (FBIL), which maintains the official data regarding the MIBOR. Even, NSE uses MIBOR rate as the appropriate riskfree interest rate for the settlement mechanism.

Due to the difference in the holidays of banking and exchange, we have used the previous day MIBOR rate for the missing value. The annualized dividend yield has been taken from the National Stock Exchange of India.

Along the lines of previous studies such as Cornell and French (1983), Neal (1996), Brailsford and Hodsgon (1997), Mcmillan and Ulku (2009), Roll et al., (2007), Richie et al., (2008), Nandan et al., (2014), Qin et al. (2019) we have computed the theoretical price as follows:

$$
F(t, T)=S e^{(r-d)(T-t) / 365}
$$

Where, $\mathrm{F}(\mathrm{t}, \mathrm{T})$ is the futures price at time $t$ for a contract that matures at time $\mathrm{T}$,

$\mathrm{S}(\mathrm{t})$ is the value of the underlying stock price at time $t$,

$\mathrm{r}$ is the risk-free interest rate,

$\mathrm{d}$ is the annualized dividend yield between $t$ and $\mathrm{T}$.

Mispricing $=($ Actual Futures price - Theoretical futures price $) /$ spot price

$$
\text { Mispricing }=\left(F(m t, T)-\mathrm{Se}^{(\mathrm{r}-\mathrm{d})(\mathrm{T}-\mathrm{t}) / 365}\right) / \mathrm{S}_{\mathrm{o}}
$$

Where, $\mathrm{F}(\mathrm{mt}, \mathrm{T})$ is the actual market price at time $t$ for a contact that matures at time $\mathrm{T}$,

$\mathrm{S}_{\mathrm{o}}$ is the spot price.

The mispricing is calculated as the difference between the actual futures price and theoretical futures price normalized by spot prices. The disconnect between the actual futures price and the theoretical futures price gives rise to pricing errors in the futures contract. Suppose the actual price of the futures contract is more than the theoretical price. In that case, the arbitrageurs will make a profit by undertaking a short position in the futures contract and a long position in the underlying index. On the other hand, if the actual price is less than the theoretical price, the arbitrageurs will prefer to buy the futures contract and sell the underlying index.

Since the near-term contracts have been considered to analyze the pricing errors, it would be interesting to note the week wise structure of mispricing in futures contracts. Ordinary least square (OLS) is used to study the pricing errors for a week to expiry effect. In our regression equation, the dependent variable is the daily mispricing series. The independent variables are dummy variables such as D1, D2, D3, D4, D5 for the first week to expiry, the second week to expiry, the third week to expiry, the fourth week to expiry and the last week to expiry respectively. The equation is as follows:

$$
R_{t}^{m p}=\sum_{i=1}^{5} \alpha_{\mathrm{i}} \mathrm{D}_{\mathrm{it}}+\gamma R_{\mathrm{t}-1}+\varepsilon_{t}
$$

Where $D_{\text {it }}$ assumes the value 0 and 1 in the form of a dummy variable, $D_{i t}=1$ for the first week to expiry, 0 otherwise. Here ' $i$ ' depicts the first, second, third, fourth and last week to expiry. Furthermore, the lag value of the dependent variable that is the mispricing series has been introduced in the model to avoid the autocorrelation in the error term. The presence of autocorrelation is confirmed with the low values of the Durbin-Watson statistic. Considering the lag ruled out the autocorrelation in the error term, making it fit for the regression model.

With the help of regression analysis, the week wise structure of mispricing in different sectoral indices has been analyzed. The dummy variables include D4 for the months which have four weeks to expiry in a near month contract and D5 for the months having five weeks to expiry in a near month contract. 
The weekends have been excluded while allocating the dummy variable to the near-term contracts to avoid the weekend effect. The last week to expiry, i.e. D5 or D4 (as the case may be) has four days before last Thursday, other weeks, i.e. except last week has five days.

The choice of the sectors is based on the trading activity among the indices and the liquidity. Among the seven indices, only three have been considered fit for the study as the rest have either low trading activity or negligible liquidity in the futures contracts. The selected indices are distinct in the behaviours as they represent entirely different sectors indicating the movements in specific industries.

\section{Results and Discussion}

In this section, we examine the key findings of the study. The paper deals with the mispricing among the sectoral indices and not only the benchmark index. The primary outcome remains consistent with the theory that as the liquidity decreases, the magnitude of mispricing increases. The results are in line with the previous studies Butterworth and Holmes (2000), Oehmke (2009) and Shankar et al. (2015). It is reported that the in all three indices the first week of expiry, observes significant mispricing and towards the last week of expiry the magnitude of mispricing becomes insignificant as the theoretical futures price converges to the actual futures price.

Table 1: Results for ADF test for stationarity

\begin{tabular}{ll}
\hline & Mispricing \\
\hline Nifty & -7.4306 \\
Bank Nifty & $(0.0000)^{* *}$ \\
Nifty IT & -8.9425 \\
& $(0.0000)^{* * *}$ \\
\hline
\end{tabular}

Note: To check the stationarity, the Augmented Dickey-Fuller (ADF) test has been applied in the study. The result of table 1 shows that the rejection of the null hypothesis, thereby indicating that the data is stationary.

Table 2: Summary statistics of week wise mispricing in Nifty

\begin{tabular}{lccccc}
\hline & D1 & D2 & D3 & D4 & D5 \\
\hline Mean & 0.0002 & 0.0001 & 0 & -0.0007 & -0.001 \\
Maximum & 0.0118 & 0.008 & 0.0225 & 0.0094 & 0.0203 \\
Minimum & -0.0101 & -0.01779 & -0.0194 & -0.0179 & -0.0084 \\
Std dev & 0.0008 & 0.0011 & 0.0013 & 0.001 & 0.0012 \\
Skewness & 1.5391 & -7.3726 & 4.1819 & -4.6128 & 5.1051 \\
Kurtosis & 97.8924 & 119.3634 & 148.5593 & 79.5916 & 103.6418 \\
obs. & 1231 & 1231 & 1231 & 1231 & 1231 \\
\hline
\end{tabular}

Note: This table reports the summary statistics of mispricing in Nifty calculated by cost of carry model [(F(mt, T) - Se(r-d)(T-t)/365)/1 So]. The sample consists of 1231 observations for the time period 2014-2018. 
Table 3: Summary statistics of week wise mispricing in Bank Nifty

\begin{tabular}{lccccc} 
& D1 & D2 & D3 & D4 & D5 \\
\hline Mean & 0.00005 & 0.0001 & -0.0001 & -0.0005 & -0.0014 \\
Maximum & 0.0033 & 0.005 & 0.0053 & 0.0059 & 0.0088 \\
Minimum & -0.0035 & -0.005 & -0.0047 & -0.0072 & -0.0099 \\
Std dev & 0.0005 & 0.0008 & 0.0009 & 0.0011 & 0.0011 \\
Skewness & -0.5229 & -0.1496 & -0.1769 & -1.8814 & -2.9502 \\
Kurtosis & 18.8256 & 14.3677 & 10.9386 & 15.03706 & 25.7606 \\
obs. & 1231 & 1231 & 1231 & 1231 & 1231 \\
\hline
\end{tabular}

Note: This table reports the summary statistics of mispricing in Bank Nifty calculated by cost of carry model $\left[\left(\mathrm{F}(\mathrm{mt}, \mathrm{T})\right.\right.$ - Se ${ }^{(r-d)(T-}$ t)/365) / So ]. The sample consists of 1231 observations for the time period 2014-2018

Table 4: Summary statistics of week wise mispricing in Nifty IT

\begin{tabular}{lccccc}
\hline & D1 & D2 & D3 & D4 & D5 \\
\hline Mean & 0.0002 & 0.0001 & 0 & -0.0007 & -0.001 \\
Maximum & 0.0266 & 0.0168 & 0.0127 & 0.0176 & 0.0407 \\
Minimum & -0.0306 & -0.035 & -0.0231 & -0.0216 & -0.0213 \\
Std dev & 0.0015 & 0.0019 & 0.0015 & 0.0015 & 0.002 \\
Skewness & -1.03494 & -9.2509 & -3.7752 & -2.1931 & 6.4059 \\
Kurtosis & 218.9431 & 153.5895 & 65.9674 & 57.7752 & 174.7106 \\
Obs. & 1231 & 1231 & 1231 & 1231 & 1231 \\
\hline
\end{tabular}

Note: This table reports the summary statistics of mispricing in Bank Nifty IT calculated by cost of carry model [(F(mt,T) - Serrd)(T-t)/365) / So]. The sample consists of 1231 observations for the period 2014-2018.

The summary statistics of mispricing among the sectoral indices in India clearly shows the existence of mispricing in the futures market. The indices are highly underpriced for the year 2014-2018. The possible explanation for persistent underpricing in the futures market could be the restrictions on short selling. If the actual price of the futures contract is less than the theoretical price, the arbitrage trade would include a long position in the futures and short position in the respective underlying index. The mispricing is found to be more in the sectoral indices than the benchmark index. For time to maturity, it is noticed that the findings are entirely different for the different sectors. The results are consistent with the previous studies of larger underpricing than overpricing Lin et al., Kempf (1998), Pope and Yadav (1994), Brenner et al. (1989), Gay and Jung (1999), Vipul (2005), Cummings and Frino (2011), Lepoene (2019), Cornell and French (1983) and Modest and Sundaresan (1983). Both the sectoral indices and the benchmark index observe the underpricing in the futures contract.

Table 5 reports the result of the OLS regression. We observe that last week to expiry effect is not statistically significant in all three indices, which is consistent with the literature. Further, if we analyze our result indices wise, we find that in the Nifty IT is having mispricing (statistically significant) in all weeks except last week. Further, Nifty (benchmark index) is having mispricing (statistically significant) in the first two weeks, and Bank Nifty is having significant mispricing in the only first week of the contract. This highlights that Nifty IT mispricing has the most extended life as compared to the other two indices.

The possible explanation for such an exciting finding could be liquidity scenario in all three indices. The liquidity is observed highest in the Bank Nifty and the lowest in the Nifty IT. Liquidity implies more trading activities in those indices, which further means more information in the market. It explains the difference in the mispricing in these indices. Indices with the highest liquidity are having the shortest life of mispricing and vice versa. 
Table 5: Regression results of sectoral indices with a week to expiry effects

\begin{tabular}{lccccc}
\hline & D1 & D2 & D3 & D4 & D5 \\
\hline Niffy & -0.0009 & -0.0005 & 0.00004 & 0.0000 & 0.0002 \\
& $(4.4894)^{* * *}$ & $(3.7818)^{* * *}$ & $(0.7589)$ & $(0.6596)$ & $(0.1693)$ \\
\hline Bank Niffy & -0.0006 & -0.0001 & 0.0000 & 0.0000 & -0.0000 \\
& $(-5.6732)^{* * *}$ & $(-1.2472)$ & $(0.5852)$ & $(0.7119)$ & $(-0.4459)$ \\
\hline Niffy IT & -0.0009 & -0.0007 & -0.0005 & -0.0005 & -0.0001 \\
& $(-2.9845)^{*}$ & $(3.4720)^{* * *}$ & $(-2.4701)^{*}$ & $(2.6402)^{* * *}$ & $(-0.4627)$ \\
\hline
\end{tabular}

Note: This table reports the regression results of sectoral indices, namely Nifty, Bank Nifty and Nifty IT with a week to expiry effects. The dependent variable is the daily mispricing series, and the independent variables are dummy variables such as DI, D2, D3, D4, D5 for the first week to expiry, the second week to expiry, third week to expiry, fourth week to expiry and last week to expiry respectively. We estimate the pricing errors for a week to expiry effect using equation $R_{t}^{m p}=\sum_{i=1}^{5} \alpha_{\mathrm{i}} \mathrm{D}_{\mathrm{it}}+\gamma R_{\mathrm{t}-1}+\varepsilon_{t}$ where $D_{i t}$ is the week wise dummy variable and 'i' depict for the first week to expiry, the second week to expiry, the third week to expiry, the fourth week to expiry and last week to expiry. The numbers in the parentheses indicate the t statistics. The level of significance is depicted as $*$ at $0.05,{ }^{* *}$ at 0.01 and ${ }^{* * *}$ at 0.001 .

\section{Conclusion}

The study highlights the pricing errors in the three indices in India. It highlights that life of pricing errors are different in the different index, which proves why it is essential to study the sectoral indices apart from the benchmark index. Along with this, the study empirically demonstrates the inverse relationship between liquidity and life of mispricing. The higher liquidity gives lesser mispricing, which is consistent with the theory as well as previous studies such as Butterworth and Holmes (2000), Ohemke (2009) and Shankar et al. (2015). For time to expiry, the mispricing is reported to be insignificant in the last week of expiry as the traders tend to wind up their positions minimizing the scope for profitable opportunities in the last week of expiry. Furthermore, in the first week to expiry, the magnitude of mispricing is relatively large as compared to the other weeks. The study focuses on the magnitude of the mispricing rather than the direction, emphasizing the inverse relationship between liquidity and the life of the mispricing. The higher chances of the mispricing in the less liquid index have strings attached to it as it will also have a greater risk.

\section{References}

Andreou, P. C., \& Pierides, Y. A. (2008). Empirical investigation of stock index futures market efficiency: the case of the Athens Derivatives Exchange. European Journal of Finance, 14(3), 21 1-223.

Bailey, W. (1989). The market for Japanese stock index futures: Some preliminary evidence. The Journal of Futures Markets (1986-1998), 9(4), $283 .$.

Bhatt, S., \& Cakici, N. (1990). Premiums on stock index futures-some evidence. The Journal of Futures Markets (1986-1998), 10(4), 367.

Brailsford, T., \& Hodgson, A. (1997). Mispricing in stock index futures: A reexamination using the SPI. Australian Journal of Management, 22(1), 21-45.

Brenner, M., Subrahmanyam, M. G., \& Uno, J. (1989). Arbitrage opportunities in the Japanese stock and futures markets. Financial Analysts Journal, 46(2), 14-24.

Bühler, W., \& Kempf, A. (1995). DAX index futures: Mispricing and arbitrage in German markets. Journal of Futures Markets, 15(7), 833-859. 
Butterworth, D., \& Holmes, P. (2000). Mispricing in stock index futures contracts: Evidence for the FTSE 100 and FTSE mid 250 contracts. Applied Economics Letters, 7(12), 795-801

Chu, Q. C., \& Hsieh, W. L. G. (2002). Pricing efficiency of the S\&P 500 index market: Evidence from the Standard \& Poor's Depositary Receipts. Journal of Futures Markets: Futures, Options, and Other Derivative Products, 22(9), 877-900.

Cornell, B., \& French, K. R. (1983). The pricing of stock index futures. Journal of Futures Markets, 3(1), 1-14.

Cummings, J. R., \& Frino, A. (2011). Index arbitrage and the pricing relationship between Australian stock index futures and their underlying shares. Accounting \& Finance, 51 (3), 661-683.

Draper, P., \& Fung, J. K. (2003). Discretionary government intervention and the mispricing of index futures. Journal of Futures Markets: Futures, Options, and Other Derivative Products, 23(12), $1159-1189$.

Fassas, A. (2010). Mispricing in stock index futures markets the case of Greece. www.researchgate.net/profile/Athanasios_Fassas/publication/228317936_Mispricing_in_Stock_Index_ Futures Markets the Case of Greece/links/55263ad20cf24b8 22b4078d3.pdf. Retrieved on 20 July, 2018.

Figlewski, S. (1984). Explaining the early discounts on stock index futures: The case for disequilibrium. FinancialAnalystsJournal, 40(4),43-47.

Figlewski, S. (2016). "Derivatives Valuation Based on Arbitrage: The Trade is Crucial", Journal of Futures Markets, Vol. 37 No.4, pp.316-327.

Fung, J. K., \& Draper, P. (1999). Mispricing of index futures contracts and short sales constraints. Journal of Futures Markets: Futures, Options, and Other Derivative Products, 19(6), 695-715.

Gay, G. D., \& Jung, D. Y. (1999). A further look at transaction costs, short sale restrictions, and futures market efficiency: the case of Korean stock index futures. Journal of Futures Markets: Futures, Options, and Other Derivative Products, 19(2), 153-174.

Gupta, V., Singh, S. and Yadav, S.S. (2019), "Impact of anchor investors on IPO returns during pre-market and aftermarket: evidence from India", Journal of Advances in Management Research, Vol. 17 (3), 351 368.

Kempf, A. (1998). Short selling, unwinding and mispricing. Journal of Futures Markets: Futures, Options, and Other Derivative Products, 18(8), 903-923.

Lai, Y. W., Lin, C. F., \& Tang, M. L. (2017). Mispricing and trader positions in the S\&P 500 index futures market. The North American Journal of Economics and Finance, 42, 250- 265.

Lepone, A., Wen, J., Wong, J. B., \& Yang, J. Y. (2019). Short selling restrictions and index futures pricing: Evidence from China. International Review of Economics \& Finance, 61, 179-187.

MacKinlay, A. C., \& Ramaswamy, K. (1988). Index-futures arbitrage and the behavior of stock index futures prices. The Review of Financial Studies, 1 (2), 137-158.

Marcinkiewicz, E. (2016). Short Sale and Index Futures Mispricing: Evidence from the Warsaw Stock Exchange. Prague Economic Papers, 2016(5), 547-559.

McMillan, D. G., \& Ülkü, N. (2009). Persistent mispricing in a recently opened emerging index futures market: Arbitrageurs invited. Journal of Futures Markets: Futures, Options, and Other Derivative Products, 29 (3), 218 243.

Modest, D. M., \& Sundaresan, M. (1983). The relationship between spot and futures prices in stock index futures markets: Some preliminary evidence. Journal of Futures Markets, 3(1), 15-41. 
Neal, R. (1996). Direct tests of index arbitrage models. Journal of Financial and Quantitative Analysis, 31 (4), 541-562.

Nandan, T., Agrawal, P., \& Bhargava, S. (2014). Mispricing in CNX nifty futures: An empirical investigation. Asia-Pacific Journal of Management Research and Innovation, 10(4), 413-422.

Oehmke, M. 2009. Gradual arbitrage, working paper. Columbia University

Qin, J., Green, C. J., \& Sirichand, K. (2019). Determinants of Nikkei futures mispricing in international markets: Dividend clustering, currency risk, and transaction costs. Journal of Futures Markets, 39(10), $1269-1300$.

Richie, N., Daigler, R. T., \& Gleason, K. C. (2008). The limits to stock index arbitrage: Examining S\&P 500 futures and SPDRS. Journal of Futures Markets: Futures, Options, and Other Derivative Products, 28(12), 1182-1205.

Roll, R., Schwartz, E., \& Subrahmanyam, A. (2007). Liquidity and the law of one price: the case of the futurescash basis. The Journal of Finance, 62 (5), 2201-2234.

Sánchez-Verdasco, J. (2016). Stock Market Efficiency under the Cost of Carry Model. Evidence from the Spanish Market. Journal Of Insurance And Financial Management, 2(2), 18-33.

Shankar, R. L., Sankar, G., \& Kumar, K. (2015). Mispricing in single stock future. NSE Working Paper. Retrieved on 25 March, 2018. https://www.nseindia.com/research Lcontent/res WorkingPaper Nov2015.pdf

Verdasco, J. S. (2016). Stock Market Efficiency Under the Cost of Carry Model. Evidence from the Spanish Market. Journal of Insurance and Financial Management, 2(2), 19-33.

Vipul. (2005). Temporal variation in futures mispricing. Vikalpa, 30(4), 25-38.

Yadav, P. K., \& Pope, P. F. (1990). Stock index futures arbitrage: International evidence. Journal of Futures Markets, 10(6), 573-603.

Yadav, P. K., \& Pope, P. F. (1994). Stock index futures mispricing: profit opportunities or risk premia? Journal of Banking \& Finance, 18(5), 921-953. 